\title{
Rotary Bayonets for Cryogenic and Vacuum Service
}

\author{
R.A. Rucinski, K.D. Dixon, R. Krasa, K.J. Krempetz, G.T. Mulholland, \\ G.R. Trotter and J.B. Urbin \\ Fermi National Accelerator Laboratory \\ P.O. Box 500, Batavia, Illinois 60510
}

July 1993

Presented at the Cryogenic Engineering Conference, Alberquerque, New Mexico, July 12-16, 1993 


\section{Disclaimer}

This report was prepared as an account of work sponsored by an agency of the United States Government. Neither the United States Government nor any agency thereof, nor any of their employees, makes any warranty, express or implied, or assumes any legal liability or responsibility for the accuracy, completeness, or usefulness of any information, apparatus, product, or process disclosed, or represents that its use would not infringe privately owned rights. Reference herein to any specific commercial product, process, or service by trade name, trademark, manufacturer, or otherwise, does not necessarily constitute or imply its endorsement, recommendation, or favoring by the United States Government or any agency thereof. The views and opinions of authors expressed herein do not necessarily state or reflect those of the United States Government or any agency thereof. 


\title{
ROTARY BAYONETS FOR CRYOGENIC AND VACUUM SERVICE*
}

\author{
R. A. Rucinski, K. D. Dixon, R. Krasa, K. J. Krempetz, \\ G. T. Mulholland, G. R. Trotter, J. B. Urbin \\ Fermi National Accelerator Laboratory \\ P. O. Box 500 \\ Batavia, IL 60510
}

\begin{abstract}
Rotary bayonets were designed, tested, and installed for liquid nitrogen, liquid argon, and vacuum service. This paper will present the design, testing, and service record for two sizes of vacuum jacketed cryogenic rotary bayonets and two sizes of vacuum service rotary bayonets. Materials used in construction provide electrical isolation across the bayonet joint. The joint permits 360 degrees of rotation between the male and female pipe sections while maintaining integrity of service. Assemblies using three such joints were built to allow end connection points to be translated through at least 1 meter of horizontal travel while kept in service. Vacuum jacketed sizes built in-house at Fermi National Accelerator Laboratory are 1 1/2" inner pipe size, 3" vacuum jacket, and 4" inner pipe size, 6 " vacuum jacket. The single wall vacuum service bayonets are in 4 " and $6^{\prime \prime}$ pipe sizes. The bayonets have successfully been in active service for over one year.
\end{abstract}

\section{Introduction}

Rotary bayonets have been developed at Fermi National Accelerator Laboratory for use at the D-Zero detector facility. Translational movements of cryogenic and vacuum service lines are required. This was accomplished by making special two piece "u-tubes" with a rotary bayonet on each end. The two piece "u-tubes" travel with a scissor-like motion as the fixed piping translates through 1 meter of motion. Each rotary bayonet end also provides electrical isolation along the piping run.

The basic design of the D-Zero detector has one $19 \mathrm{~kL}$ and two $12 \mathrm{~kL}$ liquid argon calorimeters in line along the particle accelerator's beamline. The two outer calorimeters are required to roll away from the center calorimeter while in operation. Due to the compact nature of the physics detectors, sufficient room for a conventional flexible hose solution was not available. Services that use rotary bayonets are listed in Table 1 .

* Work supported by the U.S. Department of Energy under contract No. DE-AC02-76CH03000. 
Table 1. Services provided through rotary bayonet assemblies

\section{Service}

Fill \& Drain line

Gas return line

Condenser supply

Vent line

Utility vacuum

Insulating vacuum
Eluid

Liquid Argon

Saturated GAr

Liquid Nitrogen

Sat. GN2 or GAr

N/A

N/A
Type of bayonet

$11 / 2^{n} \times 3^{n}$

$11 / 2^{n} \times 3^{n}$

$11 / 2^{n} \times 3^{n}$

$4^{n} \times 6^{n}$

$4^{\prime \prime}$

$6^{n}$

The services are connected to the detector platform through conventional one piece u-tubes that have a rotary bayonet on one end to provide electrical isolation. Once on the platform, the services run to the outermost calorimeters having services passing through the rotary bayonet u-tube assemblies. See figure 1 for the arrangement of the nested rotary bayonet assemblies. The rotary bayonet joints are represented by the small rectangular boxes.
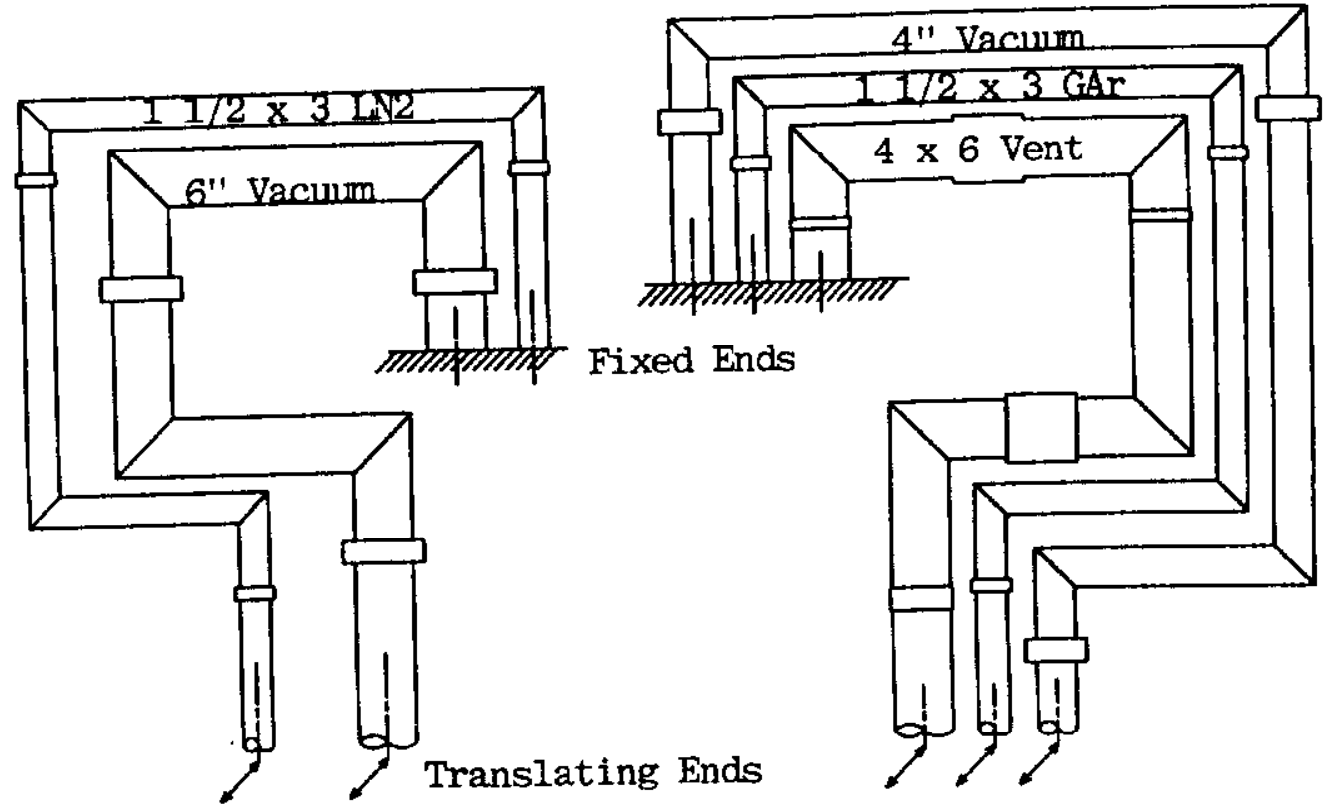

Figure 1. Arrangement of nested rotary bayonet assemblies that allow translation of piping ends. 


\section{Development}

A commercially available rotary bayonet was available from Cryolab. This commercial design was carefully considered and tested, and found not to be a satisfactory solution.

Fermilab designed its own rotary bayonets. Fermilab differed from the Cryolab design using a separate ultra high molecular weight (UHMW) polyethylene o-ring carrier, different connection arrangement and other electrical isolation features. Figure 2 shows the assembly detail for the cryogenic and vacuum rotary bayonets. The assembly detail for the other sizes is similar. Some specific data about each size is listed in table 2 . The maximum internal design pressures for the bayonets are $0.8 \mathrm{Mpa}(100 \mathrm{psig})$.

Table 2. Bayonet sizes and data for each

$\begin{array}{lllll}\text { Bayonet size } & \begin{array}{l}\text { Mated set } \\ \text { length }\end{array} & \begin{array}{l}\text { Male stinger } \\ \text { length }\end{array} & \begin{array}{l}\text { Male stinger } \\ \text { Qutsidedia. }\end{array} & \begin{array}{l}\text { Female } \\ \text { inside dia }\end{array} \\ 11 / 2^{\prime \prime} \times 3^{\prime \prime} \text { pipe size } & 50.5 \mathrm{~cm}\left(19.9^{\prime \prime}\right) & 44.2 \mathrm{~cm}\left(17.4^{\prime \prime}\right) & 6.35 \mathrm{~cm}\left(2.50^{\prime \prime}\right) & 6.65 \mathrm{~cm}\left(2.62^{\prime \prime}\right) \\ 4^{\prime \prime} \times 6^{\prime \prime} \text { pipe size } & 51.6 \mathrm{~cm}\left(20.3^{\prime \prime}\right) & 45.0 \mathrm{~cm}\left(17.7^{\prime \prime}\right) & 13.2 \mathrm{~cm}\left(5.19^{\prime \prime}\right) & 13.6 \mathrm{~cm}\left(5.34^{\prime \prime}\right) \\ 4^{\prime \prime} \text { pipe size } & 27.9 \mathrm{~cm}\left(11.0^{n}\right) & 14.3 \mathrm{~cm}\left(5.63^{\prime \prime}\right) & 10.9 \mathrm{~cm}\left(4.28^{\prime \prime}\right) & 11.7 \mathrm{~cm}\left(4.63^{\prime \prime}\right) \\ 6^{\prime \prime} \text { pipe size } & 33.0 \mathrm{cn}\left(13.0^{n}\right) & 19.4 \mathrm{~cm}\left(7.63^{\prime \prime}\right) & 16.3 \mathrm{~cm}\left(6.40^{\prime \prime}\right) & 17.1 \mathrm{~cm}\left(6.75^{\prime \prime}\right)\end{array}$

The cryogenic bayonets have the following features. The male stinger tip has a groove that holds a UHMW lower bearing. The lower bearing is machined and then slit along one side to allow it to be attached to the stinger. This lower bearing keeps the stinger tip from electrically contacting the female part and spins freely to allow rotation. The top of the male stinger has a lip that rides on the surface of the o-ring carrier. The UHMW o-ring carrier holds two inner and two outer o-rings to make a radial seal against the male and female parts of the bayonet. The top surface of the male stinger's lip is held down by a brass nut with a Teflon bearing. The female part of the bayonet is similar to a standard stationary bayonet. Except for the UHMW and Teflon bearings, Buna $\mathrm{N}$ orings, and brass nut, the bayonet is made of type 304 stainless steel. The lower bearing, o-ring carrier, and Teflon bearing keep the male part electrically isolated from the female part.

The vacuum service bayonets also use a UHMW lower bearing. The lower bearing for these sizes are only partially slit and are soaked in hot water to be slipped onto the male stinger. The top of the male stinger has a lip that rides on a UHMW rotary seal flange. The rotary seal flange has a double o-ring that makes a radial seal against the male stinger. The lower surface of the rotary seal flange rests on the flanged portion of the female part. This flange has double o-ring grooves. A top flange with Teflon bearing captures the male stinger's lip and sandwiches the rotary seal flange. Bolts fasten the top flange to the flange on the female part. The rotary seal flange does not rotate with rotation of the male part. A few wraps of Kapton electrical tape inside the top flange area completes the electrical isolation of the male and female parts. Except for the bearings, and o-rings, the bayonet is made of 304 stainless steel. A small sample tubing is connected to the space between the double o-rings for pumping or diagnostic purposes. On the basis of the success of the vacuum service bayonets, this tubing is capped after installation testing. O-rings of all the bayonets were lightly lubricated with a silicone based vacuum grease during assembly. 

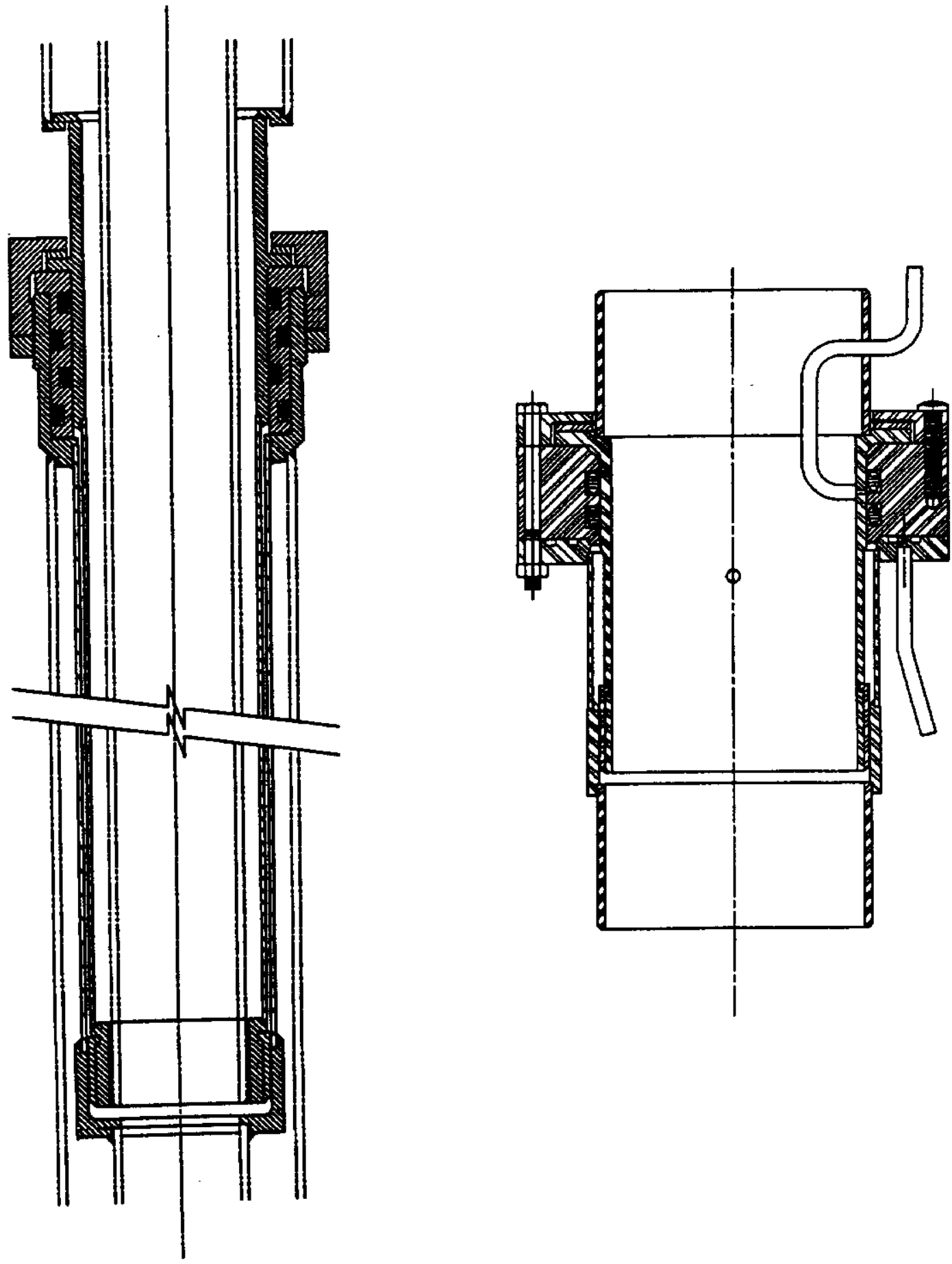

Figure 2. Sectional view of $11 / 2^{n} \times 3^{n}$ cryogenic rotary bayonet and 4" vacuum connector rotary bayonet. 


\section{Testing}

Extensive parameter and life tests were performed on the rotary bayonets before installation into the D-Zero detector. Rotation tests were performed first. The cryogenic bayonets were mounted on a stand with a $76 \mathrm{~cm}$ lever arm attached to the male part. This lever arm was coupled to a linear track that resulted in a back and forth rotation of the bayonet through about ninety degrees. A liquid nitrogen vessel was fitted to the top of the male and kept full. The bayonets were at cryogenic temperatures and 50 to 90 psi pressure during the tests. A majority of the turns were done with a $9 \mathrm{~kg}$ load brick resting on the end of the lever arm to simulate a misalignment. A helium mass spectrometer leak detector (HMSLD) with a sensitivity of better than $1 \times 10 \mathrm{E}-9 \mathrm{~atm}-\mathrm{cc} / \mathrm{s} \mathrm{He}$, showed no leakage before or after the tests. The $6^{\prime \prime}$ vacuum bayonet was tested in a similar fashion but was under vacuum service during the turns. The vacuum level of the isolated bayonet stayed below 1 micron pressure during the testing which lasted more than two weeks. A HMSLD check also showed no leaks before or after the test. The 4 " vacuum bayonet was not tested.

The special two piece $u$-tube assemblies that allow translation were tested. A single assembly made of the $11 / 2^{\prime \prime} \times 3^{\prime \prime}$ size bayonets was tested first. One female end was fixed to the floor and the other female end was mounted on a linear track that traveled back and forth through 1 meter. The two piece a-tubes were in between, pivoting in a scissor type motion. The piping was pressurized to 90 psig with helium gas and a hand held helium leak detector was used to sniff the joints while the assembly was in motion. The assembly was misaligned to the vertical by as much as 2.7 degrees, yet no binding or leakage was detected. The force required to move the assembly ranged from 65 to 260 Newtons (15 to $60 \mathrm{lbf}$ ). The two groups of nested assemblies shown in figure 1 were tested. The cryogenic service bayonets were pressurized and sniffed for leakage similar to the previously described test. The vacuum service bayonets were isolated under vacuum and monitored for pressure increase. No leaks were detected and the vacuum pressure rise observed was attributed to outgassing.

Table 3. Summary of tests performed on rotary bayonets

Size/Test performed

$11 / 2^{n} \times 3^{\prime \prime}, 8027$ turns at liquid nitrogen temperature

$4^{\prime \prime} \times 6^{\prime \prime}, 5423$ turns at liquid nitrogen temperature

6" vacuum connector, 4845 turns under vacuum

$11 / 2^{\prime \prime} \times 3^{\prime \prime}$, Assembly translated with misalignment

Two nested assemblies translating, 13 trips

Three nested assemblies translating

\section{Result}

No leakage detected

No leakage detected

No leakage, maintained $<1$ micron pressure

No binding, smooth motion, no leaks

No binding, smooth motion, no leaks

No binding, smooth motion, no leaks

\section{Service Record}

The bayonet assemblies were installed and put into service in the fall of 1991 . During start up, one leaking joint was discovered and repaired. This failure was due to using the incorrect o-ring size during assembly, and then scuffing it when inserting the male. No other leaks occurred in the last year and a half of service. The assemblies are in a static position $99.8 \%$ of the time. They have been articulated through their travel approximately 20 times. One planned upgrade to the assemblies is the addition of rotary bayonet stops which will enable the assemblies to scissor in only one direction. Without this feature the floating pivot of the assembly could get ahead of the moving one causing damage to the piping. This type of accident occurred early in the operation of the detector. The two u-tube sections did not unfold but crossed instead and bent the piping 
by several inches. Since that incident, we have stationed observers during all detector moves to ensure the proper fold out action. The cryogenic service bayonets run cool locally at the brass nut joints. The temperature measured is $280 \mathrm{~K}$. Condensation is sometimes observed locally in this area. Height requirements kept the bayonets short, perhaps a longer version would lessen this nuisance.

\section{Conclusions}

The rotary bayonets have been a success. The $\mathrm{D}$-Zero detector has forty-two rotary bayonet joints in service. Thirty-six of these rotary bayonet joints are used in special two piece u-tube assemblies that articulate while kept in service. There have been no leaks or problems observed with the vacuum service bayonets. The vacuum jacketed rotary bayonets have almost faired as well with the only problem being cold condensating joints. The rotary bayonet design provided a solution to electrically isolated joints and moveable piping in the limited space of the D-Zero detector. 